\title{
Polymeric implant of methylprednisolone for spinal injury: preparation and characterization
}

\author{
Bo Yin ${ }^{1}$, Jian-Jun $\mathrm{Ji}^{1 *}$ and Ming Yang ${ }^{2}$ \\ ${ }^{1}$ Department of Orthopedics, People's Hospital of Zoucheng, Jining, Shandong 273500, ${ }^{2}$ Department of Orthopedic Trauma, \\ Peking University People's Hospital, Beijing 100000, PR China
}

*For correspondence: Email: jianjun066@hotmail.com; Tel/Fax: 0086-537-5250877

\begin{abstract}
Purpose: To improve the effectiveness and reduce the systemic side effects of methylprednisolone in traumatic spinal injuries, its polymeric implants were prepared using chitosan and sodium alginate as the biocompatible polymers.

Methods: Implants of methylprednisolone sodium succinate (MPSS) were prepared by molding the drug-loaded polymeric mass obtained after ionotropic gelation method. The prepared implants were evaluated for drug loading, in vitro drug release and in vivo performance in traumatic spinal-injury rat model with paraplegia.

Results: All the implant formulations were light pale solid matrix with smooth texture. Implants showed $86.56 \pm 2.07 \%$ drug loading. Drug release was $89.29 \pm 1.25 \%$ at the end of 7 days. Motor function was evaluated in traumatic spinal injury-induced rats in terms of its movement on the horizontal bar. At the end of 7 days, the test group showed the activity score $(4.75 \pm 0.02)$ slightly higher than that of standard $(4.62 \pm 0.25)$, but the difference was not statistically different $(p>0.05)$.

Conclusion: MPSS-loaded implants produces good recovery in traumatic spinal-injury rats.
\end{abstract}

Keywords: Spinal injury, Spinal column, Methylprednisolone, Implant, Activity score, Motor function

Tropical Journal of Pharmaceutical Research is indexed by Science Citation Index (SciSearch), Scopus, International Pharmaceutical Abstract, Chemical Abstracts, Embase, Index Copernicus, EBSCO, African Index Medicus, JournalSeek, Journal Citation Reports/Science Edition, Directory of Open Access Journals (DOAJ), African Journal Online, Bioline International, Open-J-Gate and Pharmacy Abstracts

\section{INTRODUCTION}

Implants are invasive polymeric delivery devices which are intended to release the drug in the injected/inserted body cavity in a very slow manner for prolonged periods of time which may extend from a week to few months and even to many years. These may be prepared either from non-biodegradable polymers or from biodegradable polymers. Non-biodegradable implants are needed to be removed by another surgical procedure after the expected completion of drug in the polymeric implant. Though invasive nature of procedures is a limitation of use of implant, easy termination of therapy (if required in case of adverse effects) by removal of implant is a unique advantage of implants. Unlike conventional parenteral dosage forms drug delivery by implants can reduce dosage frequency, provide prolonged duration of action and improve the patient compliance [1,2]. Implants can deliver drug in the microenvironment of target site or in vicinity of target site with maximizing the drug utilization and providing local as well as systemic effects. Implants may be solid matrix type or reservoir type devices with or without special drug releasing mechanisms like molds, tablets, pellets, osmotic pumps, infusion pumps etc. or may be in situ gelling systems which upon injection get converted in to a gel with contact of body fluids, change in temperature or $\mathrm{pH}[3,4]$. 
Spinal column is the most sophisticated and complex biological target site for drug delivery. Traumatic spinal cord injury is one of the most complex injuries to manage. Spinal injury leads to permanent disability, paraplegia, tetraplegia and over all decreased life expectancy [5-7]. There is no cure of spinal cord injury but efforts can be made to cope with the effects of primary and secondary spinal injury.

The management of neuropathic pain and inflammation is the prime objective in treatment of spinal injuries. Many potent nonsteroidal antiinflammatory drugs (NSAIDs) and steroids (in high dosage) are administered for the same. But to provide the prolonged and target specific drug delivery various NSAIDs and steroids have been investigated for intrathecal administration so as to provide improved therapeutic effect $[8,9]$. Various biodegradable polymers have been investigated for preparing scaffolds or polymeric network/platform/implant of developing for neuroprotective and neuroregenerative drug delivery systems in spinal cord injuries [10,11].

Methylprednisolone sodium succinate (MPSS) is the glucocorticoid used in effective management of traumatic spinal injury [12]. It has been reported to show significant recovery from tissue damage, neuropathic pain and inflammation. Studies have also shown improvement in motor nerve activity with the use of MPSS in spinal injury $[13,14]$. This study aims to develop the polymeric implantable device of MPSS and to study its effect on traumatic spinal injured rats with paraplegia.

\section{EXPERIMENTAL}

\section{Materials}

Methylprednisolone sodium succinate (MPSS), chitosan $75 \%$ deacylated and sodium alginate (SA) were obtained from Sigma Aldrich Japan. Rests of the chemicals were of analytical grade.

\section{Preparation of polymeric hydrogels of MPSS}

Implants of MPSS were prepared by molding of drug loaded polymeric mass obtained after the ionotropic gelation method (Table 1). Accurately weighed quantity of sodium alginate was dispersed in distilled water and stirred at $200 \mathrm{rpm}$ for $30 \mathrm{~min}$ meanwhile weighed quantity of the drug was dispersed onto the dispersion of alginate. This drug-alginate solution was mixed with $4 \%$ solution of chitosan in acetone with stirring with addition of propylene glycol. Then this solution was kept in teflon molds with flat bottom and slowly $2 \%$ aqueous calcium chloride solution was sprayed for 10 minutes till the mass attained the gel like consistency. The molds containing polymeric matrix loaded with the drug was frozen at $-10 \pm 1{ }^{\circ} \mathrm{C}$ for rigidization overnight. The prepared implant molds were taken out to room temperature and then cut into small cubic pieces of desired size with a surgical blade. For hardening these implants were kept in a desiccator rich in vapors of formaldehyde which were produced by keeping $37 \% \mathrm{v} / \mathrm{v}$ formaldehyde solution at the bottom of the desiccator for $48 \mathrm{~h}$. After hardening, the implants were taken out, air dried for 4 days for removing traces of formaldehyde from the implants. Finally the prepared implants were sterilized by ethylene oxide and then packed in butter paper for storage in cool dark place in an aseptic environment.

Table 1: Composition of polymeric implant of MPSS

\begin{tabular}{lc}
\hline Ingredient & Content \\
\hline $\begin{array}{l}\text { MPSS } \\
(\% \mathrm{w} / \mathrm{w})\end{array}$ & 1 \\
$\begin{array}{l}\text { Sodium alginate } \\
(\% \mathrm{w} / \mathrm{w})\end{array}$ & 2 \\
$\begin{array}{l}\text { Chitosan* } \\
(\% \mathrm{w} / \mathrm{w})\end{array}$ & 1 \\
$\begin{array}{l}\text { Polypropylene glycol } \\
(\% \mathrm{v} / \mathrm{v})\end{array}$ & 5 \\
\hline${ }^{*}$ Chitosan solution was prepared in acetone $4 \% \mathrm{w} / \mathrm{v}$
\end{tabular}

\section{Drug loading}

One implant $(15 \times 15 \times 15 \mathrm{~mm})$ was dissolved in $50 \mathrm{ml}$ of methanol with continuous stirring (200 $\mathrm{rpm})$ at $\left.37 \pm 1^{\circ} \mathrm{C}\right)$ for $1 \mathrm{~h}(\mathrm{n}=6)$. One $\mathrm{mL}$ sample was withdrawn, diluted suitably and then analysed spectrophotometrically.

\section{In vitro release of drug}

In vitro drug release study was performed according to a reported method [15]. One implant $(15 \times 15 \times 15 \mathrm{~mm})$ was kept in a tightly closed vial with $\mathrm{pH} 7.4$ buffer $(10 \mathrm{ml})$ as media. Several such vials were kept on an incubator shaker (at $37 \pm 1.0^{\circ} \mathrm{C}$ ). For taking sample a single vial was withdrawn at definite time interval till 7 days and analysed spectrophotometrically for drug release $(n=3)$.

\section{In vivo study on traumatic spinal-injury rats}

Healthy male Wistar rats $(200-240 \mathrm{~g})$ were used for the study. After procurement, experiment was carried after giving 3 - 4 days of resting and acclimatization. The rats were fed standard diet and water ad libitum. Protocols of the study were duly approved (approval no. 2014/A243) by 
Animal Ethical Committee of Peking University. In vivo study was executed as per directives of European Commission on animal handling [16].

A total of 54 rats were divided in three groups (control, standard and test group) of eighteen rats each. All the animals were subjected to laminectomy (after injecting thiopental sodium 40 $\mathrm{mg} / \mathrm{kg}$ ) by giving the acute spinal injury by compression method (extradural $50 \mathrm{~g}$ force clip for $10 \mathrm{~s}$ at around T2) laterally after giving thiopental sodium $(40 \mathrm{mg} / \mathrm{kg})$. Immediately the control groups were administered the nonmedicated implant. The test group received the polymeric implant of MPSS $(50 \mathrm{mg} / \mathrm{Kg}$ body weight; i.t.) near injury. MPSS was injected i.v. at $30 \mathrm{mg} / \mathrm{Kg}$ body weight in the Standard after $1 \mathrm{~h}$ of injury (and given the same at every alternate day for one week). At the end of 7 days, the locomotor activity was observed by the performance of rats in Horizontal Bar. The experiment was performed on an apparatus with a horizontal bar $(2 \mathrm{~mm}$ diameter; $40 \mathrm{~cm}$ long) fitted on two support of $50 \mathrm{~cm}$ height. By holding the mouse tail it was left on the bar with the help of its forepaw's contact in the center of the bar. The time spent by rats in horizontal bar was studied and scoring was done on the basis of following scale: $1-5 \mathrm{sec}=1 ; 6-10 \mathrm{sec}=2 ; 11$ $20 \mathrm{sec}=3 ; 21-30 \mathrm{sec}=4 ;>30 \mathrm{sec}=5$; bar support touch with forepaw $=5$.

\section{Statistical analysis}

The results are expressed as mean \pm standard deviation (SD). $P<0.05$ was considered statistically significant.

\section{RESULTS}

Chitosan and alginate blend based polymeric implants loaded with MPSS were prepared by

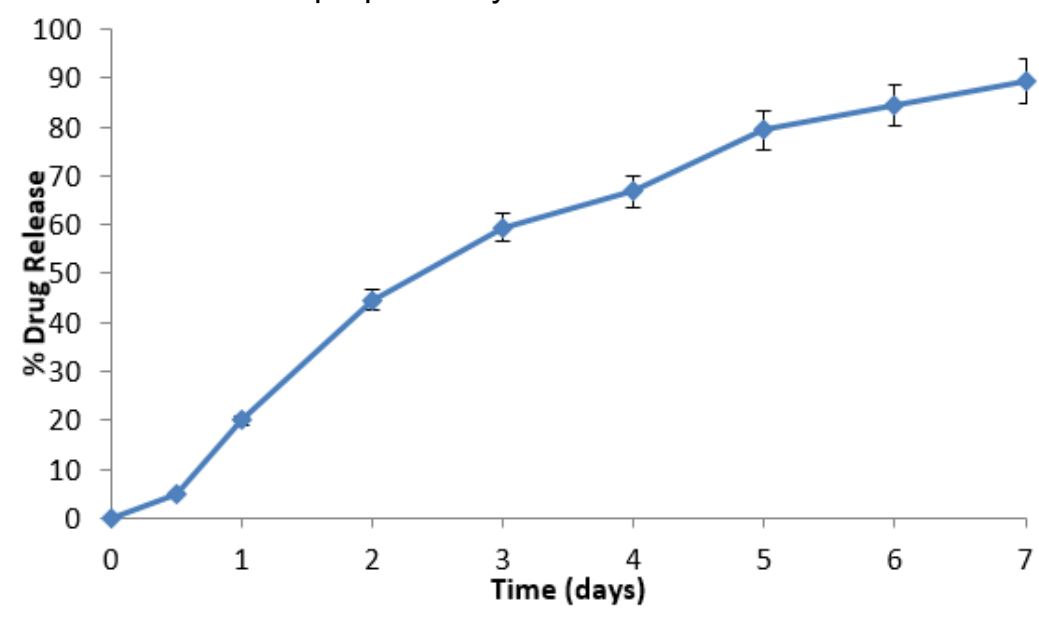

Fig 1: In vitro drug release study of polymeric implant of Methylprednisolone in $\mathrm{pH} 7.4$ phosphate buffer ionotropic gelation method and characterized for drug loading, in vitro drug release and in vivo performance in traumatic spinal injured rats. The method used is simple and easy to reproduce.

The implants were observed as the light pale solid matrix with smooth texture. Implants showed $86.56 \pm 2.07 \%$ drug loading. Drug release was $89.29 \pm 1.25 \%$ at the end of 7 days (Fig 1). Alginate chitosan blend of polymer have been reported to provide controlled drug release in various previous studies $[17,18]$.

Locomotor activity is governed by motor nerve activity which is adversely affected by spinal injury. Therefore, motor activity of the traumatic spinal injured rats were compared after administering the prepared implants of MPSS with that of standard (i.v. MPSS). Motor function was evaluated in terms of the rat's movement in a horizontal bar (Table 2). After the 24 hours no improvement in activity was observed in any group (activity score $0.40 \pm 0.02$ ). Moreover, out of 18 rats in control group only 7 survived. All 18 survived in standard (activity score: $0.41 \pm 0.20$ ) and 16 survived in test group (activity score: 0.42 \pm 0.12) with insignificant improvement. As survival was quite good in test group animals it was inferred that the polymeric device was well tolerated in the subjects.

On the day 4, there was still no significant improvement in activity (activity score: $0.42 \pm$ 0.12 ) in control group which remain only 4 . The standard group showed activity score of $2.45 \pm$ 1.20 at the end of day 4 with little tail lifting. On the other hand the test group showed better activity than that of standards with activity score of $3.20 \pm 0.20$. 
Table 2: In vivo locomotor activity of polymeric implant of MPSS in traumatic spinal injured rats

\begin{tabular}{lccc}
\hline Group & \multicolumn{3}{c}{ Activity score $^{\star *}$} \\
\cline { 2 - 4 } & Day 1 $^{\mathrm{a}}$ & Day 4 $^{\mathrm{b}}$ & Day 7 $^{\mathrm{c}}$ \\
\hline Control & $0.40 \pm 0.02$ & $0.42 \pm 0.12$ & $0.45 \pm 0.10$ \\
Standard & $0.41 \pm 0.20^{\mathrm{a}}$ & $2.45 \pm 1.20^{\mathrm{a}}$ & $4.62 \pm 0.25^{\mathrm{a}}$ \\
Test & $0.42 \pm 0.12^{\mathrm{a}}$ & $3.20 \pm 0.20^{\mathrm{a}}$ & $4.75 \pm 0.02^{\mathrm{a}}$ \\
\hline
\end{tabular}

* MPSS: methylprednisolone sodium succinate i.v., $50 \mathrm{mg} / \mathrm{Kg}$ body weight; ${ }^{* *}$ Activity scoring: $1-5 \mathrm{sec}=1 ; 6-10$

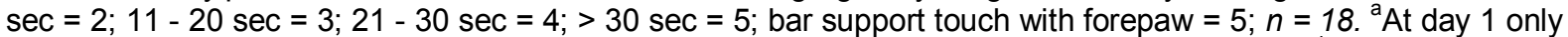
7 survived out of 18 in control; all 18 survived in standard while 16 survived in test group.; ${ }^{b}$ At day 4 only 7 survived in control; no further deaths was there in standard and test group.; ${ }^{c}$ At day 7 only 2 survived in control but there was no death in standard and test; ${ }^{d} p<0.05$ vs. control

At the end of the day 7 only 2 rats survived in control with no sign of improvement in the activity score $(0.45 \pm 0.10)$. The standard group showed an activity score of $4.62 \pm 0.25$ while the test group had an activity score of $4.75 \pm 0.02$ which is insignificantly $(p<0.05)$ different from that of standard.

\section{DISCUSSION}

It has been shown by various previous studies that the implants prepared from biodegradable polymers are one of the most potential approaches of delivering drugs to target site. Delivering a drug in the microenvironment of target site ensures the maximum drug utilization with minimum drug dosage. Moreover, as drug is not distributed peripherally much, the adverse effects of the drug are also minimized $[19,20]$. In polymeric devices selection of biocompatible polymers and/or solvents is crucial to minimize chances of rejection of the devices by the subjects [21].

Biodegradable polymers have been investigated for various pharmaceutical drug delivery systems. Apart from being nontoxic, nonmutagenic and non-cytotoxic, the biodegradable polymers are metabolized in the body and eliminated by normal physiological pathways $[22,23]$. Methylprednisolone is a potent antiinflammatory glucocorticoid which is used as a very first line treatment in cases of post traumatic $\mathrm{SCl}$. It was reported to show significant recovery from primary tissue damage and secondary neuropathic pain and inflammation. Studies have also shown improvement in motor nerve activity with use of $\mathrm{Mp}$ in $\mathrm{SCl}[14,15,24]$.

Most of the studies have demonstrated positive effects of MPSS in SCl with parenteral (i.v.) administration. But high dosage of MPSS is also associated with the systemic adverse effects. Therefore, alternative routes or devices (like biodegradable implants) for administration of MPSS have been explored and investigated. Biodegradable implantable drug delivery techniques have been designed to release drugs at the targeted site like fractured vertebra, injured spinal cord etc. for prolonged period of time. But it requires surgical procedure for administering the implant devices to the target site [2-4].

In a recent study, in situ gel prepared from chitosan and PLGA (1:14) was found to be very potential in the post traumatic spinal injuries. The in situ gel showed high drug content, satisfactory rheological properties, prolonged drug release and the best in vivo anti-inflammatory and motor function activity performance [25]. This recent study also supported the use of implant for delivering MPSS in SCl. The prepared implant of MPSS showed the high \% drug loading which is the prerequisite for the drug delivery systems for accommodating desired quantity of drug within the delivery matrix for subsequent slow diffusion or release of the drug. The in vitro drug release study of the prepared implant showed a slow and prolonged drug release which had been well supported by the various previous studies dealing with the alginate chitosan polymeric drug delivery matrix $[17,18]$. The prepared implants of MPSS showed motor activity in the traumatic spinal injured rats that was comparable to that of the standard (intravenous MPSS).

\section{CONCLUSION}

The findings of this study indicate that MPSS implants show high drug loading, prolonged in vitro drug release and good tolerance in rats. The implants also produces significant recovery in traumatic spinal injured rats. These implants may be useful for providing prolonged drug release and improved recovery in patients of traumatic spinal injury, but this has to be first confirmed in human experiments.

\section{DECLARATIONS}

\section{Acknowledgement}

Authors acknowledge People's Hospital of Zoucheng, Jining and Peking University People's Hospital, Beijing for the kind support. 


\section{Conflict of Interest}

No conflict of interest associated with this work.

\section{Contribution of Authors}

The authors declare that this work was done by the authors named in this article and all liabilities pertaining to claims relating to the content of this article will be borne by them.

\section{REFERENCES}

1. Shi Y, Li LC. Current advances in sustained-release systems for parenteral drug delivery. Expert Opin Drug Deliv 2005; 2(6): 1039-1058.

2. Iyer SS, Barr WH, Dance ME, Coleman PR, Karnes HT. A 'biorelevant' system to investigate in vitro drug released from a naltrexone implant. Int J Pharm 2007; 340: 104-1018.

3. lyer SS, Barr WH, Karnes HT. Profiling in vitro drug release from subcutaneous implants: A review of current status and potential implications on drug product development. Biopharm Drug Dispos 2006; 27: 157-170.

4. Nitsch MJ, Banakar UV. Implant drug delivery. J Biomater Appl 1994; 8: 247-284.

5. Chiono V, Tonda-Turo C, Ciardelli G Artificial scaffolds for peripheral nerve reconstruction. Int Rev Neurobiol 2009; 87: 173-198.

6. Madigan NN, McMahon S, O'Brien T, Yaszemski AJ, Windebank MJ. Current tissue engineering and novel therapeutic approaches to axonal regeneration following spinal cord injury using polymer scaffolds. J Respir Physiol Neurobiol 2009; 169: 183-199.

7. Norman LL, Stroka K, Espinoza HA. Guiding axons in the central nervous system. Tissue Eng Part B 2009; 15: 291-305.

8. Alvarez-Mejia L., Morales J, Cruz GJ, Olayo MG, Olayo $R$, Díaz-Ruíz A, Ríos C, Mondragón-Lozano $R$, Sánchez-Torres S, Morales-Guadarrama A, FabelaSánchez O, Salgado-Ceballos H. Functional recovery in spinal cord injured rats using polypyrrole/iodine implants and treadmill training. J Mater Sci Mater Med. 2015; 26(7): 5541-5547.

9. Chen $B$, He J, Yang $H$, Zhang $Q$, Zhang L, Zhang X, Xie $E$, Liu C, Zhang $R$, Wang $Y$, Huang $L$, Hao $D$. Repair of spinal cord injury by implantation of bFGF-incorporated HEMA-MOETACL hydrogel in rats. Sci Rep 2015; 12(5): 9017-9019.

10. Wang S, Kempen DHR, Ruiter GCW, Cai L, Spinner RJ, Windebank AJ , Yaszemski MJ, Lu L. Molecularly engineered biodegradable polymer networks with a wide range of stiffness for bone and peripheral nerve regeneration. Adv Funct Mater 2015; 25: 2715-2724.

11. Hurlbert RJ, Hadley MN, Walters BC, Aarabi B, Dhall SS, Gelb DE, Rozzelle CJ, Ryken TC, Theodore N.
Pharmacological therapy for acute spinal cord injury. Neurosurgery. 2015; 76(1): S71-83.

12. Grant RA, Quon JL, Abbed KM. Management of acute traumatic spinal cord injury. Curr Treat Options Neurol. 2015; 17(2): 334-339.

13. Akhtar AZ, Pippin JJ, Sandusky CB. Animal studies in spinal cord injury. A systematic review of methylprednisolone. ATLA. 2009; 37: 43-62.

14. Taoka Y, Okajima K, Uchiba $M$, Johno $M$. Methylprednisolone reduces spinal cord injury in rats without affecting tumor necrosis factor-alpha production. J Neurotrauma. 2001; 18: 533-543.

15. Gokhan E, Mine O, Ercument K, Mesut A, Tamer G. Invitro programmable implants for constant drug release. Acta Pharm Tur 2005; 47: 243-256.

16. European Commission [homepage on the internet]. Directive 2010/63/EU on the protection of animals used for scientific purposes [cited 2015 July 08]. Available from: $\quad$ http://ec.europa.eu/environment/chemicals/lab _animals/legislation_en.htm.

17. Lanjhiyana SK, Bajpayee $P$, Kesavan K, Lanjhiyana S, Muthu $M$ S. Chitosan-sodium alginate blended polyelectrolyte complexes as potential multiparticulate carrier system: colon-targeted delivery and gamma scintigraphic imaging. Expert Opin Drug Deliv 2013; 10(1): 5-15

18. Liu Y, Liu HL, Sun J, Sang LL, XU HC. Orthopedic implants of ketorolac in vertebral fracture: Development, physicochemical, preclinical and clinical evaluation. J Biomater Tissue Eng 2015; 5: 323-322.

19. Jimenez HMC, Tsai EC, Tator CH, Shoichet MS. Novel intrathecal delivery system for treatment of spinal cord injury. Exp Neurol. 2003; 182(2): 300-309.

20. Kang CE, Poon PC, Tator $C H$, Shoichet MS. A new paradigm for local and sustained release of therapeutic molecules to the injured spinal cord for neuroprotection and tissue repair. Tissue Eng Part A. 2009; 15(3): 595504.

21. Yan S, Wang T, Feng L, Zhu J, Zhang $K$, Chen $X$, Cui L, Yin J. Injectable in situ self-cross-linking hydrogels based on poly (L-glutamic acid) and alginate for cartilage tissue engineering. Biomacromolecules 2014; 15(12): 4495-4508.

22. Zee MV. Biodegradability of polymers-Mechanism and evaluation methods. In Handbook of biodegradable polymers. Bastioli, C., Eds. Shropshire, Rapra Technology Limited. 2005: 1-31.

23. Gao C, Gao J, You X, Huo S, Li X, Zhang Y, Zhang W. Fabrication of calcium sulfate/PLGA composite for bone repair. J Biomedical Material Res. 2005; 73: 244-253.

24. Kim DH, Jahng TA. Continuous brain-derived neurotrophic factor (BDNF) infusion after methylprednisolone treatment in severe spinal cord injury. J Korean Med Sci. 2004; 19: 113-122.

25. Che YJ, Chen L, Lv GH, Wang XB. In situ gel delivery system of methylprednisolone for post traumatic spinal injuries. J Biomater Tissue Eng 2015; 5: 552-556. 